\title{
Evaluation of Polymer Alternating Waterflooding in Multilayered Heterogeneous Waterflooded Reservoir
}

\author{
Warut Tuncharoen \\ Department of Mining and Petroleum Engineering \\ Chulalongkorn University \\ Bangkok, Thailand \\ Email: warut.t@student.chula.ac.th
}

\begin{abstract}
Polymer flooding is widely implemented to improve oil recovery since polymer can increase sweep efficiency and smoothen heterogeneous reservoir profile. However, polymer solution is somewhat difficult to be injected due to high viscosity and thus, water slug is recommended to be injected before and during polymer injection in order to increase an ease of injecting this viscous fluid into the wellbore. In this study, numerical simulation is performed to determine the most appropriate operating parameters to maximize oil recovery. The results show that pre-flushed water should be injected until water breakthrough while alternating water slug size should be as low as $5 \%$ of polymer slug size. Concentration for each polymer slugs should be kept constant and recommended number of alternative cycles is 2 . Combining these operating parameters altogether contributes to oil recovery of $53.69 \%$ whereas single-slug polymer flooding provides only $53.04 \%$ which is equivalent to $8,000 \mathrm{STB}$ of oil gain.
\end{abstract}

Keywords-Polymer flooding; Polymer Injectivity; Concentration Sorting; Number of Alternative Cycle

\section{INTRODUCTION}

In recent years, oil price has plunged below satisfaction for the oil producers which triggered them to save any cost as much as possible especially, the cost of exploring and drilling new wells so, various oil recovery techniques are developed to extend the oil production life. Waterflooding used to be a common technique to increase the amount of oil owing to its simplicity and cost-effectiveness. However, waterflooding has one major problem which happens when water bypasses oil to the highest permeability channel, leaving some amounts of oil non-displaced due to unfavorable mobility of water compared to that of oil.

Instead of solely water, one benefit of polymer over water is that it creates more viscous fluid. Thus, when polymer solution is injected into the reservoir, polymer solution with higher viscous force will sweep more oil to the production well comparing to conventional waterflooding. Another benefit of polymer solution is that certain types of polymer tend to be adsorbed onto rock surface which results in reduction of the flow area of water, causing relative permeability to water to reduce and consequently, sweep efficiency is increased and more oil is produced.

\author{
Falan Srisuriyachai \\ Department of Mining and Petroleum Engineering \\ Chulalongkorn University \\ Bangkok, Thailand \\ Email: falan.s@chula.ac.th
}

However, the injection of solely polymer solution into a well still has a drawback. A major problem is that the ability to inject polymer into the reservoir as known as "injectivity" is low since polymer itself is very viscous so, the desired injection rate is scarcely achieved. Moreover, high adsorption of polymer onto rock surface could cause adverse effect on high reduction of flow ability. Therefore, water should be injected in between to increase the injectivity of polymer. Moreover, water would result in desorption of polymer on the rock surface which provides more ease for injecting the following polymer slugs.

\section{POLYMER FLOODING IN HETEROGENEOUS RESERVOIR}

\section{A. Mobility Control Mechanism}

Typically, polymer has two major characteristics affecting the increment of oil production; first, polymer is more viscous than water, when it is mixed with water, viscosity of water is increased. This reduces mobility ratio between water and oil to favorable condition which is when mobility ratio is less than one. Second, polymer tends to adsorb onto rock surface, thus, water has difficulty traveling through pore spaces, causing relative permeability to water to decline and turning mobility ratio to a favorable condition also.

Mobility ratio can be obtained from the following equation:

$$
M=\frac{\lambda_{w}}{\lambda_{o}}=\frac{k_{r w} / \mu_{w}}{k_{r o} / \mu_{o}}
$$

When, $M=$ Mobility Ratio

$\lambda_{w}=$ Mobility of Water

$\lambda_{o}=$ Mobility of Oil

$k_{r w}=$ Relative Permeability to Water

$k_{r o}=$ Relative Permeability to Oil

$\mu_{w}=$ Viscosity of Water

$\mu_{o}=$ Viscosity of Oil 
Mobility ratio implies relative speed between two fluids. In case of unfavorable condition $(M>1)$, water travels faster than oil and tends to breakthrough first, on the other hand, oil travels faster than water in case of favorable condition $(M<1)$

\section{B. Relative Permeability Reduction}

Apart from increasing the viscosity of water, polymer solution also has effect on reduction of relative permeability to water without affecting the relative permeability to oil [1]. Considering mobility ratio equation, when relative permeability to water decreases, mobility ratio tends to decrease and converge to a more favorable condition $(M<1)$.

There are two main measures in permeable media flow which are resistance factor $(R F)$ and residual resistance factor $(R R F)$

1. Resistance Factor $(R F)$ : a relative pressure drop caused by polymer flooding and waterflooding. By using Darcy's Law, this term can be written as a mobility ratio between water and polymer as follows:

$$
R F=\frac{\Delta p_{\text {polymer }}}{\Delta p_{\text {water }}}=\frac{\lambda_{\text {water }}}{\lambda_{\text {polymer }}}
$$

2. Residual Resistance Factor $(R R F)$ : the ratio between relative permeability to water and water after polymer flooding, also known as "Permeability Reduction"

$$
R R F=\frac{k_{r w, \text { beforepolymer.flooding }}}{k_{r w, \text { after.polymer.flooding }}}
$$

\section{Polymer Flow Behavior in Porous Media}

\section{a. Inaccessible Pore Volume (IPV)}

$I P V$ happens when larger polymer molecule is introduced into the reservoir and cannot flow through smaller pore space of rock. The volume of uninvaded pore space is known as Inaccessible Pore Volume (IPV) [2]. Factors that affect $I P V$ include polymer molecular weight, permeability-porosity of rock and pore size distribution.

\section{b. Polymer Retention}

Polymer retention consists of three main mechanisms which are polymer adsorption, mechanical entrapment and hydrodynamic retention.

1. Polymer Adsorption: the charge interaction between polymer and rock surface causes polymer molecule to be adsorbed onto rock surface. Thus, some part of polymer mass will be removed from bulk polymer solution in this interaction. Polymer adsorption depends upon surface area of rock exposed to polymer solution.

2. Mechanical Entrapment: this mechanism contributes a major part of polymer retention. It usually occurs in low-permeability formation. Since polymer is flexible, when it is trapped in a pore channel, a fluid can still flow through a polymer chain and brings even more polymer into a channel, resulting in an accumulation of polymer in a channel.

3. Hydrodynamic Retention: this mechanism is similar to mechanical entrapment except that trapped polymer molecule can be released when fluid does not flow through pore channel anymore [3].

\section{Reservoir Heterogeneity}

Reservoir Heterogeneity is defined as the variation of rock properties in different locations within the reservoir. One of the significant rock properties affecting heterogeneity is permeability. Combination of permeability can be classified into Parallel Layer and Serial Layer. Moreover, the heterogeneity of reservoir can be quantified by several methods. One of the widely used method is Lorenz Coefficent $\left(L_{k}\right)$ which can be acquired from Fig. 1 by ratio of area 1 and area 2 . If $L_{k}$ is close to zero, reservoir is considered to have a uniform permeability distribution [4].

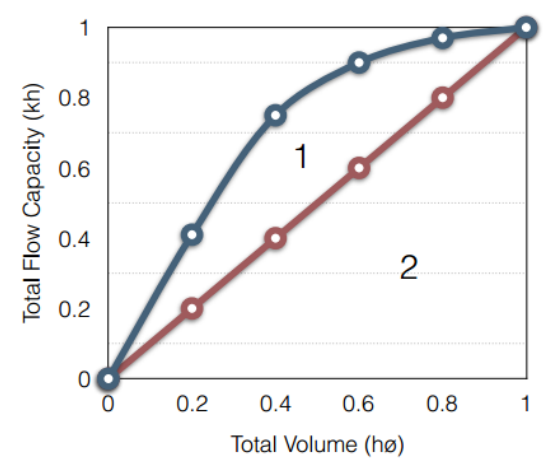

Fig. 1. Flow Capacity Distribution for determination of Lorenz Coefficient

\section{METHODOLOGY}

After theory of polymer flooding has been reviewed, all the procedures to achieve the purpose of this study are listed and described in this section.

1. Construct heterogeneous model with single Lorenz coefficient at $L_{k}=0.275$ with coarsening upward sequence

2. Perform waterflooding from the start of oil production to be a reference for other polymer flooding cases

3. Perform single-slug polymer flooding with polymer concentration of $1,000 \mathrm{ppm}$ and $0.25 \mathrm{PV}$ slug size to determine:

- Polymer Injection Starting Time: first day of production, after injecting $25 \%$ of water before breakthrough, after injecting $50 \%$ of water before breakthrough, at water breakthrough, after watercut reaches $25 \%$, and after watercut reaches $50 \%$.

4. Perform polymer alternating waterflooding. Keep the same injected polymer mass while varying the following operating parameters: 
- Concentration Sorting: descending order, ascending order

- Alternating Water Slug Size: 5\%, 10\%, 25\%, 50\%, $100 \%$ (same size) of polymer slug size

- Number of Alternative Cycles: 1, 2, 3, 4, 5

5. Compare and analyze the results, using outcome parameters such as oil recovery factor, production time, etc.

Reservoir simulation model is generated using Cartesian grid model. The reservoir is heterogeneous with $L_{k}$ of 0.275 . Other important reservoir properties are shown in TABLE I as follows:

TABLE I. RESERVIR PROPERTIES FOR BASE CASE MODEL

\begin{tabular}{|c|c|c|}
\hline Parameters & Values & Unit \\
\hline Grid dimension & $33 \times 33 \times 9$ & Block \\
\hline Grid size & $20 \times 20 \times 12$ & $\mathrm{ft}$. \\
\hline Top of reservoir & 7,000 & $\mathrm{ft}$. \\
\hline Effective porosity $(\varnothing)$ & 20 & $\%$ \\
\hline Average permeability $\left(k_{v}=k_{h}\right)$ & 230 & $\mathrm{mD}$ \\
\hline Initial water saturation $\left(S_{w i}\right)$ & 20 & $\%$ \\
\hline Reference pressure at datum depth & 3,445 & $\mathrm{psia}$ \\
\hline Reservoir temperature & 182 & ${ }^{\circ} \mathrm{F}$ \\
\hline Oil gravity & 20 & ${ }^{\circ} \mathrm{API}$ \\
\hline Solution gas oil ratio $\left(R_{s}\right)$ & 50 & $\mathrm{scf} / \mathrm{stb}$ \\
\hline Original oil in place $(O O I P)$ & $1,276.71$ & $\mathrm{MMstb}$ \\
\hline
\end{tabular}

Hole size for both injector and producer is 6 inches. For the injector, bottomhole pressure (BHP) is limited at 4,700 psi due to fracture pressure calculated using Hubbert-Willis equation at 4,743 psi and at producer; minimum bottomhole pressure is set at 420 psi beyond the bubble point pressure of $416 \mathrm{psi}$ to continuously produce single-phase oil. Maximum injection and production rate are both operated at $800 \mathrm{STB} / \mathrm{D}$ to balance the reservoir pressure. Production will be terminated in case that watercut at producer reaches $90 \%$. Other constraints are summarized in TABLE II.

TABLE II. PRODUCTION CONSTRAINTS FOR RESERVOIR SimUlation

\begin{tabular}{|c|c|c|}
\hline Parameters & Values & Unit \\
\hline Fracture Pressure & 4,743 & $\mathrm{psi}$ \\
\hline Maximum BHP at Injector & 4,700 & $\mathrm{psi}$ \\
\hline Bubble Point Pressure & 416 & $\mathrm{psi}$ \\
\hline Minimum BHP at Producer & 420 & $\mathrm{psi}$ \\
\hline Maximum Injection Rate & 800 & $\mathrm{STB} / \mathrm{D}$ \\
\hline Maximum Production Rate & 800 & $\mathrm{STB} / \mathrm{D}$ \\
\hline Maximum Watercut at Producer & 90 & $\%$ \\
\hline
\end{tabular}

\section{RESULTS AND DISCUSSION}

In order to identify appropriate operating parameters for polymer alternating waterflooding, including polymer injection starting time, alternating water slug size, concentration sorting and number of alternative cycles, first, waterflooding is performed as a base case for other polymer flooding cases. After that, several polymer flooding cases are simulated to determine the most appropriate scenario to perform polymer alternating waterflooding.

\section{A. Waterflooding}

Waterflooding is a conventional oil recovery method performed by injecting water into the reservoir to maintain the reservoir pressure. Waterflooding will be used as a reference to determine the benefit from injecting polymer into the reservoir.

Fig. 2 shows that water starts to breakthrough at $7^{\text {th }}$ month of production which is very early because this reservoir is highly heterogeneous $\left(L_{k}=0.275\right)$ and injection rate is quite high so, water tends to flow through the highest permeability channel only. In accordance with watercut, at the early time before breakthrough, pressure support from waterflooding can maintain oil rate at 800 STB/D later, after water breakthrough, oil rate drops rapidly due to insufficient pressure support from waterflooding, finally, oil production is terminated in mid-2005 due to watercut constraint with cumulative oil production of 0.49 MMstb and oil recovery factor of $38.8 \%$.

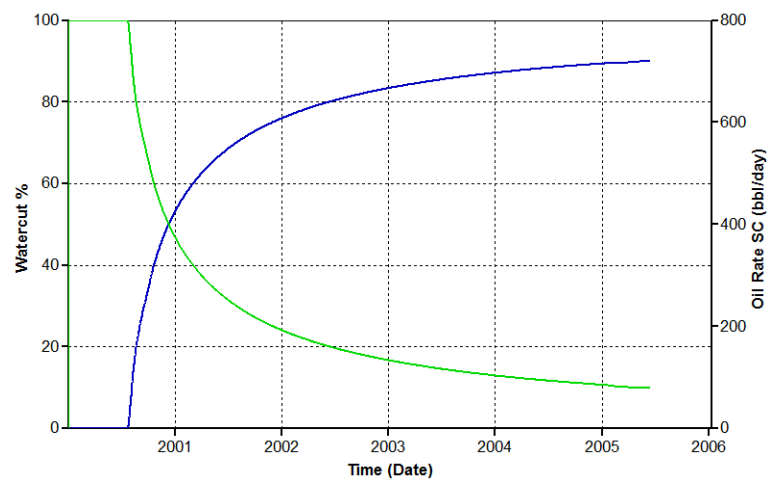

Fig. 2. Plot of watercut at producer (blue) on the left scale and oil rate (green) on the right scale as a function of time of waterflooding

\section{B. Polymer Injection Starting Time}

A quarter-five spot pattern is applied with the same production constraints used in waterflooding case. Hydrolized Polyacrylamide (HPAM) polymer is selected since it can exhibit both water viscosity enhancement and relative permeability reduction behaviors. HPAM has a molecular weight of $8,000 \mathrm{lb} / \mathrm{mol}$. Single-slug polymer flooding is performed with polymer concentration of 1,000 ppm and 0.25 PV slug size. $20 \% I P V$ and $R R F$ of 2 are assumed in this study.

One major problem of injecting solely polymer slug is that liquid injection rate cannot be attained at desired rate (800 STB/D) at the early time of production since polymer itself has low injectivity as shown in Fig. 3 (red line). 


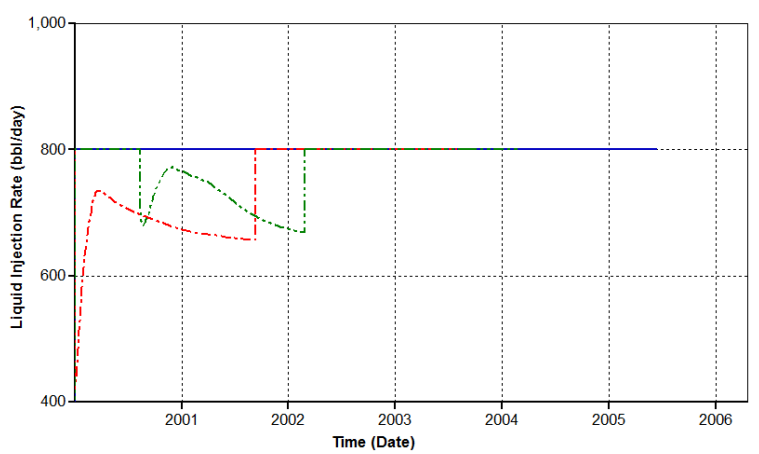

Fig. 3. Plot of liquid injection rate of polymer flooding (red), waterflooding (blue) and polymer flooding with pre-flushed water until water breakthrough (green) as a function of time

To increase injectivity of polymer, pre-flushed water is used to inject before a polymer slug. Several cases are simulated to determine which scenario will provide the best production scheme in terms of pre-flushed water and results are summarized in TABLE III.

TABLE III. RESULTS FROM DIFFERENT POLYMER INJECTION STARTING TIME

\begin{tabular}{|c|c|c|c|}
\hline No. & Scenario & $\begin{array}{c}\boldsymbol{R F} \\
(\%)\end{array}$ & $\begin{array}{c}\text { Time } \\
\text { (days) }\end{array}$ \\
\hline 1 & No Pre-flush & 51.66 & 1,308 \\
\hline 2 & Pre-flush 25\% before BT & 52.89 & 1,492 \\
\hline 3 & Pre-flush 50\% before BT & 52.71 & 1,461 \\
\hline 4 & Pre-flush until BT & 53.04 & 1,521 \\
\hline 5 & Pre-flush until 25\% watercut & 50.66 & 1,521 \\
\hline 6 & Pre-flush until 50\% watercut & 52.67 & 1,609 \\
\hline
\end{tabular}

From the table, to inject pre-flushed water until water breakthrough (case 4 ) provides the best result since polymer injection rate can mostly attain desired rate at $800 \mathrm{STB} / \mathrm{D}$ after pre-flushed water is injected as illustrated by green line in Fig. 3. If less amount of pre-flushed water is used, injected water is not sufficient to assist increasing polymer injectivity. On the other hand, if pre-flushed water is kept injecting after water breakthrough, polymer injection time will be delayed and so does the ability to improve oil displacement from polymer. Hence, to inject pre-flushed water until water breakthrough is a trade-off between injectivity and effective oil displacement mechanism.

\section{Alternating Water Slug Size}

Another thing that can improve polymer injectivity is to split polymer slug into smaller ones and separate them with water slug in between. Polymer slug is cut in half $(0.125 \mathrm{PV}$ each) to perform double-slug polymer flooding while still remaining same polymer dosage. Alternating water slug size from $5 \%, 10 \%, 25 \%, 50 \%, 100 \%$ of polymer slug size is numerical simulated to determine the best scenario as illustrated in Fig. 4.

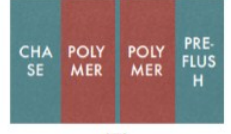

(7)

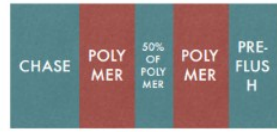

(10)
(8)

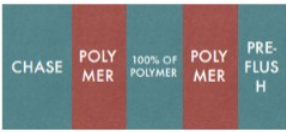

(11)

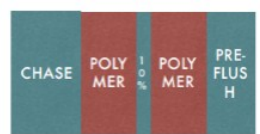

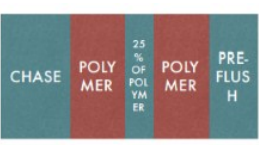

(9)
Fig. 4. Illustration of double-slug polymer flooding with different alternating water slug size

TABLE IV summarizes results in terms of oil recovery factor and total production time obtained from cases illustrated in Fig. 4. From the table, it shows that using the same alternating water slug size as polymer (case 11) provides the smallest oil recovery while using the smallest water slug at $5 \%$ of polymer (case 7 ) contributes to the highest oil recovery. This can be explained that even though it is true that if large water slug is selected, injection rate when injecting a following polymer slug will not drop much from the desired rate $(800 \mathrm{STB} / \mathrm{D})$ and it takes shorter time to inject last polymer slug but time spent during water slug injection is too much whereas the polymer injectivity from both cases is not significantly different as shown in Fig. 5. This setbacks time to inject another polymer slug. Another reason is that small amount of water is sufficient to desorb polymer on rock surface that has desorption level of $60 \%$. In case that desorption level is more than $60 \%$, more water may be required.

TABLE IV. RESULTS FROM DIFFERENT ALTERNATING WATER SLUG SIZE

\begin{tabular}{|c|c|c|c|}
\hline No. & Scenario & $\begin{array}{c}\boldsymbol{R F} \\
(\%)\end{array}$ & $\begin{array}{c}\text { Time } \\
\text { (days) }\end{array}$ \\
\hline 7 & Water : Polymer $=5 \%$ & 53.69 & 1,613 \\
\hline 8 & Water : Polymer $=10 \%$ & 53.11 & 1,521 \\
\hline 9 & Water : Polymer $=25 \%$ & 53.08 & 1,552 \\
\hline 10 & Water : Polymer $=50 \%$ & 53.17 & 1,576 \\
\hline 11 & Water : Polymer $=1: 1(100 \%)$ & 51.31 & 1,674 \\
\hline
\end{tabular}

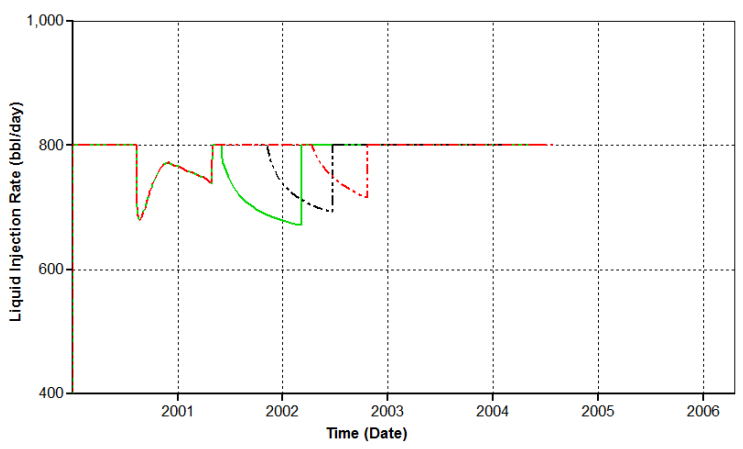

Fig. 5. Plot of liquid injection rate of double-slug polymer flooding using alternating water slug size 5\% (green), 50\% (black) and $100 \%$ (red) of polymer slug size as a function of time 


\section{Concentration Sorting}

For double-slug polymer flooding in section C, concentration of each polymer slug is as same as that of bulk polymer slug. This section will focus on the effect of concentration order of double-slug polymer flooding both in descending (high to low) and ascending (low to high) order while keeping the same polymer mass as shown in Fig. 6.

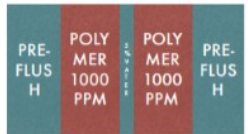

(12)

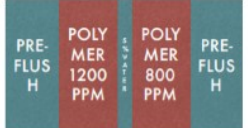

(15)

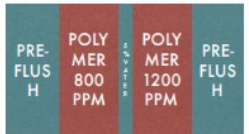

(13)

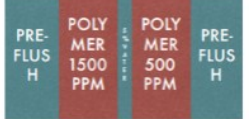

(16)
Fig. 6. Illustration of all scenarios of polymer concentration sorting

From TABLE $\mathrm{V}$ which summarizes results in this section, it is obvious that either descending or ascending order provide less oil recovery compared to case with the same concentration for all of the polymer slugs. This can be explained that for the first two descending order cases (case $13,14)$, first polymer concentration is too high for preflushed water to recover the polymer injectivity while second polymer slug has less concentration that can be injected easily but with lower polymer effect so these greatly reduces the oil recovery afterwards. In ascending cases (case 15, 16), low concentration polymer is easily injected first so, the use of pre-flushed water to increase the polymer injectivity is unnecessary while following polymer slug has more concentration that can drastically reduce the injectivity of polymer since water slug in between is only $5 \%$ of polymer slug which is insufficient to increase the injectivity.

In conclusion, polymer concentration should be balanced for each polymer slug since it can obtain optimum effect from both polymer injectivity and effectiveness.

TABLE V. RESULTS FROM DIFFERENT CONCENTRATION SORTING

\begin{tabular}{|c|c|c|c|}
\hline No. & Scenario & $\begin{array}{c}\boldsymbol{R F} \\
(\%)\end{array}$ & $\begin{array}{c}\text { Time } \\
\text { (days) }\end{array}$ \\
\hline 12 & No Sorting & 53.69 & 1,613 \\
\hline 13 & Descending $(1,200 / 800 \mathrm{ppm})$ & 51.44 & 1,582 \\
\hline 14 & Descending $(1,500 / 500 \mathrm{ppm})$ & 51.99 & 1,643 \\
\hline 15 & Ascending $(800 / 1,200 \mathrm{ppm})$ & 52.51 & 1,674 \\
\hline 16 & Ascending $(500 / 1,500 \mathrm{ppm})$ & 51.42 & 1,917 \\
\hline
\end{tabular}

\section{E. Number of Alternative Cycles}

Since a bulk polymer slug can be segregated into several smaller slugs with water slug in between to increase polymer injectivity. The exact number of polymer slugs which provides the best result will be investigated in this section. A number of alternative cycles starting from 1 to 5 cycles as recommended by previous literature [5] are simulated with the same polymer mass and bulk polymer slug is segregated equally as illustrated in Fig. 7.

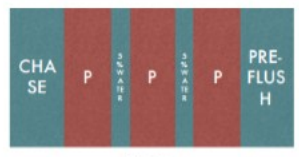

(19)

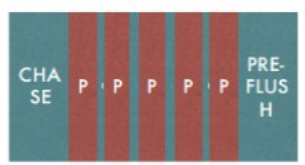

(21)

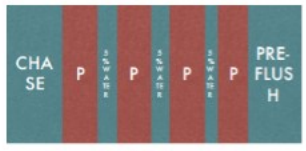

(20)
Fig. 7. Illustration of polymer alternating waterflooding with 3 cycles (19), 4 cycles (20), 5 cycles (21)

Results from TABLE VI shows that using 2 alternative cycles (case 18) contributes the highest oil recovery (slightly higher than using 3 cycles). This can be explained that the optimum alternative cycles for $0.25 \mathrm{PV}, 1,000 \mathrm{ppm}$-polymer slug to be segregated is 2 cycles, if more than 2 cycles is used (case 19,20,21), polymer dosage of each slug will be too small and not sufficient to maintain the effectiveness of polymer, resulting in relatively lower oil recovery.

TABLE VI. RESULTS FROM DIFFERENT NUMBER OF ALTERNATIVE CYCLES

\begin{tabular}{|c|c|c|c|}
\hline No. & Scenario & $\begin{array}{c}\boldsymbol{R F} \\
(\%)\end{array}$ & $\begin{array}{c}\text { Time } \\
\text { (days) }\end{array}$ \\
\hline 17 & 1 cycle & 53.04 & 1,521 \\
\hline 18 & 2 cycles & 53.69 & 1,613 \\
\hline 19 & 3 cycles & 53.66 & 1,613 \\
\hline 20 & 4 cycles & 53.56 & 1,582 \\
\hline 21 & 5 cycles & 53.61 & 1,582 \\
\hline
\end{tabular}

Oil saturation profile for double-slug polymer flooding using pre-flushed water until breakthrough, water slug of 5\% of polymer slug and same concentration for each polymer slug is illustrated in Fig. 8. The color scale shows different oil saturation starting from 0 (blue) to 1 (green). The injection sequence initiates from injecting pre-flushed water until water breakthroughs at producer (a) then, first $0.125 \mathrm{PV}$ polymer slug is followed (b). After a short period of injecting water slug (c), second polymer slug is injected (d) and finally, waterflooding is performed until the end of production (e). 


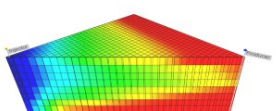

(a)

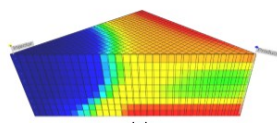

(c)

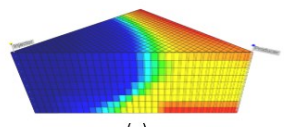

(e)

Fig. 8. Oil saturation profile of double-slug polymer flooding starting from pre-flushed water until breakthrough (a), first $0.125 \mathrm{PV}$ polymer slug (b), water slug ( $5 \%$ of polymer slug) (c), second 0.125 PV polymer slug (d), chase water until the end of production (e)

\section{CONCLUSION}

1. Waterflooding causes early water breakthrough in heterogeneous reservoir so, polymer flooding is introduced to solve this problem since polymer can be served as a mobility controller for the reservoir. However, solely polymer injection can immensely reduce the injectivity. Consequently, Polymer Alternating Waterflooding is being studied to determine the best solution for this problem.

2. Pre-flushed water is not only used to check for the connectivity between wells but it is also injected to increase injectivity before injecting polymer slug. The study shows that to inject pre-flushed water until water breakthrough yields the best result.

3. Water slug between polymer slugs has ability to improve the ease of injecting another polymer slug and it is recommended to be relatively small in size compared to polymer slug. In this study, alternating water slug size of 5\% of polymer slug contributes to the highest oil recovery.

4. Concentration of each polymer slug should be equal in order to balance the effect between polymer injectivity and oil displacement mechanism.

5. Two alternative cycles is the most appropriate cycles for $0.25 \mathrm{PV}$ polymer with $1,000 \mathrm{ppm}$. Too many cycles means each slug will be too small and will not be effective to improve oil recovery.

6. In summary, injecting two polymer slugs should be performed with pre-flushed water until breakthrough, alternating water slug of $5 \%$ of polymer slug and same concentration for each polymer slug. This will provide oil recovery of $53.69 \%$ which is $0.65 \%$ (approximately 8,000 STB) higher compared to just injecting one single polymer slug with cumulative water production of $55,000 \mathrm{bbl}$ over 1,613 days of production period.

\section{ACKNOWLEDGMENT}

The authors would like to thank to Chevron Thailand Exploration and Production, Ltd. for financial support for this study.

\section{REFERENCES}

[1] Al-Sharji, H.H., Grattoni, C.A., Dawe, R.A., Zimmerman, R.W., Disproportionate Permeability Reduction Due to Polymer Adsorption Entanglement. 2001, Society of Petroleum Engineers.Lake, L.W., Enhanced Oil Recovery. 1989: Prentice Hall.

[2] Lake, L.W., Enhanced oil recovery. 1989: Prentice Hall.

[3] Dominguez, J.G. and Willhite, G.P., Retention and Flow Characteristics of Polymer Solutions in Porous Media. 1977.

[4] Tiab, D. and Donaldson, E.C., Petrophysics: Theory and Practice of Measuring Reservoir Rock and Fluid Transport Properties. 1996: Gulf Publishing Company.

[5] Peihui, H., Haibo, L., Xu, H., Ruibo, C., Yuwei, Z., Xiaoyang, L., Alternative Injection and Its Seepage Mechanism of Polymer Flooding in Heterogeneous Reservoirs. 2015, Society of Petroleum Engineers. 